CORRECTION

\title{
Correction to: Measurable residual disease status and FLT3 inhibitor therapy in patients with FLT3-ITD mutated AML following allogeneic hematopoietic cell transplantation
}

Emily C. Liang (D), Connie Chen, Rong Lu, Gabriel N. Mannis and Lori Muffly (iD

(C) The Author(s), under exclusive licence to Springer Nature Limited 2022

Bone Marrow Transplantation (2022) 57:694; https://doi.org/10.1038/s41409-022-01606-9

Correction to: Bone Marrow Transplant https://doi.org/10.1038/ s41409-021-01475-8, published online 28 September 2021

In this article the statement in the Funding information section was incorrectly given as

"This work was partially supported by the National Institutes of Health Grant UL1-TR003142 and Grant P30-CA124435." and should have read
"This manuscript is partially supported by the Biostatistics Shared Resource (BSR) of the NIH-funded Stanford Cancer Institute: P30CA124435."

The original article has been corrected. 